\title{
DISSECTING HUMOR ON DAVID SEDARIS' ME TALK PRETTY ONE DAY BY APPLYING GENERAL THEORY OF VERBAL HUMOR
}

\author{
Sujono \\ STKIP PGRI Nganjuk, Indonesia \\ john.bril@gmail.com
}

\begin{abstract}
Understanding and perceiving humor in narrative text is not unproblematic. This is not only we have to know the background knowledge of the humor but also understanding the structure of humor in narrative text. As the winner of the Thurber Prize for American Humor at 2001, David Sedaris 'Me Talk Pretty One Day must be very funny. However, a humor can never achieve its intended effect unless the basic elements of the humor are completely self-evident. So this study is endeavored to know (1) the parts of text in David Sedaris 'Me Talk Pretty One Day that is humorous, and (2) how David Sedaris delivers the humor in this his autobiography. The research is done by descriptive qualitative. Seven very funny chapters of 27 chapters in David Sedaris' Me Talk Pretty One Day then are analyzed by Miles-Huberman's data reduction, data display and conclusion. In the data reduction, there are the narrative leveling and the selection-description of the data in terms of GTVH knowledge resources. The text is levelled into narrative level/storyline (leveln), micronarrative level (levelnn), and metanarrative level (leveln>n). The GTVH knowledge resources applied are script opposition (SO), logical mechanism (LM), situation (SI), target (TA), narrative strategy (NS), and language (LA). The data then displayed in such a matrices so that the conclusion can be drawn. From the seven chapters analyzed, it is found that 457 parts of text are humorous (457 script oppositions). The type of script opposition are normal/abnormal (68.05\%), Good vs. bad (13.57\%), Obscene vs. non-obscene (5.25\%), Possible vs. impossible (4.16\%), Correct/incorrect (2.63\%), Real vs. unreal $(2.41 \%)$, clear/unclear $(1.53 \%)$, Honest/dishonest (1.53\%), Crime/non-crime $(0.44 \%)$, realistic/unrealistic $(0.22 \%)$. serous/unserious $(0.22 \%)$. Those script oppositions are presented various logical mechanism. They are ignoring the obvious $(18.16 \%)$, analogy $(13.79 \%)$, juxtaposition (12.47\%), parallelism (11.38\%), inferring consequence $(6.56 \%)$, potency mappings $(6.35 \%)$, faulty reasoning $(5.47 \%)$, exaggeration $(5.25 \%)$, vacuous reversal $(3.28 \%)$, Coincidence $(3.28 \%)$, role-reversals $(2.63 \%)$, self undermining $(2.63 \%)$, almost situation $(2.41 \%)$, vicious circle $(1.97 \%)$, garden-path $(0.88 \%)$, implicit parallelism $(0.88 \%)$, proportion $(0.44 \%)$, field restriction $(0.44 \%)$, false analogy $(0.44 \%)$, cratylism $(0.44 \%)$, referential ambiguity $(0.44 \%)$, role exchanges $(0.22 \%)$, and figure-ground reversal $(0.22 \%)$. The humor are delivered through diffuse disjunction $59.74 \%$, ending with punch line $(28 \%)$, using metanarrative disruption $(8 \%)$, and coincidences $(3.7 \%)$. From the findings, it can be concluded that David Sedaris' Me Talk Pretty One Day is funny. However, as it is dominated by normal/abnormal opposition and delivered through diffuse disjunction, readers of David Sedaris' Me Talk Pretty One Day may find difficulties in perceiving the humor, especially non-native speaker.
\end{abstract}

Keywords: humor, me talk pretty one day, GTVH

\section{INTRODUCTION}

Having a good sense of humor is good as it has many positive effects of life. In health or physiology, numerous studies have reported that a humorous laughter reduces heart rate, blood pressure, muscle tension, and stress chemicals such as epinephrine, norepinephrine, cortisol, Dihydroxyphenylacetic acid in the blood [26]. Psychologically humor may supply self-knowledge, integrity, and mental health. Socially, it will strengthen social bonds.

Humor is also a powerful pesticide intended to help eliminate any of the hostile feelings in our daily life. The most common are sexual frustrations, intrusion of authority into our private lives, such as financial concerns, family problems, anxiety and powerlessness in the wake of technology, and the largest one that is our insecurity about our own physical characteristics, which triggers prejudices and criticisms against minorities.

On an educational field, healthy sense of humor has many beneficial effects for both the teachers and the students. First, it contributes to mind and body balance. A sense of humor can create a remarkable feeling of control. Second, it maximizes the brainpower. The surprise elements of humor alert the attention-center of the brain and increase the likelihood of memory storage and long-term retrieval. Third, it enhances creativity. Creativity is the ability of the brain to bring together diverse ideas that will generate the thinking necessary for a complex problem solving.

Humor and creativity are great companions, each a perfect complement for the other in nourishing thinking. Fourth, it facilitates Communication. Using humor to build and maintain relationships is an invaluable skill. Humor generates trust among colleagues and can facilitate a reduction in tension, fear, and anger. Fifth, it creates an Optimal Environment for Teaching and Learning. Humor contributes to that optimal learning environment. It is a brain-compatible both in creating an enriched context for learning and for assisting individuals in the learning process (Morrison, 2008:1-6).

Laughter or humor may be universal but sense of humor is not universal. Critchley (2002:67) stated that, although various forms of non-verbal humour can travel across linguistic frontiers, witness the great success enjoyed by the Commedia dell'arte throughout Europe in the sixteenth and seventeenth centuries and the enduring popularity of various forms of mime and silent comedy, such as Chaplin, Monsieur Hulot and Mr. Bean, verbal humour is notoriously recalcitrant to translation.

The capacity to understand verbal humor is dogged by Cognitive, emotional, behavioral, psychophysiological, and social components [23]. Therefore, understanding verbal humor and developing sense of humor of foreign language is hard, it involves 
many aspects of life. One of the ways to develop a sense of humor is by reading and analyzing a humorous text or book. There are things that must be considered in analyzing humor.

First a warning from [43], he said, "Humor can be dissected, as a frog can, but the thing dies in the process and the innards are discouraging to any but the pure scientific mind". Second, [42] questioned about analyzing humor, he said "How can the analysis of humor be a serious thing? Since humor itself is not to be taken seriously, why would we take its analysis seriously? Conversely, if the analysis of humor aims at seriousness does it not kill the humor and thus stand opposed to its object of study?" There are some remarks connecting with these quotes.

First, Analyzing humor may make the funniness vanished, if we do this by removing it from the context, or change the source, or change the moment, or change the audience, or change the nature of the humor (Gulas and Weinberger, 2006:139). Second, when we are reading a humorous text and do not get it, the humor has already been death. Clearly to understand a joke, for instance, is to have some explanation for its incongruous aspects, and we easily know this if we have correctly constructed this explanation (If not, someone may have to "explain" the joke to us). Further, there is nothing wrong with clarifying the humor. As stated by Petersen (2011:xx) that "Indeed, there is nothing worse than having to explain a gag; a joke can never achieve its intended effect unless the basic elements of the humor are completely selfevident.

There have been many studies corresponding to humor analysis. Amalisa (2003) did "An Analysis of Sociopragmatic across Culture on Joke in Readers' Digest". The main method used to describe and analyze the data is Raskin's Semantic Script theory of Humor (SSTH). On the other side, the quantitative method is also applied to measure the Indonesian students' ability to understand humor. What she has found are, based on SSTH Life's like that is a joke and Indonesian students of senior high school in Nganjuk are hard to perceive Life's like that to be funny.

This can be seen from their low score on the pragmatic meaning of the joke. The questionnaire data on different cultural background and the taste and vocabulary level support this. The second is Rochmawati (2011) on the title "The Rhetorical Approach to the Understanding of the Joke Texts in Readers' Digest". The methods used to describe the data are Austin's speech act theory, Grice's Cooperative principle, and Raskin and Attardo's General Theory of Verbal Humor (GTVH).

She has found many things. First, the world funniest jokes in Reader's Digest are conforming Aristotelian's text structure - orientation, event and humorous twist. Second, Austin's speech act theory is powerful in explaining the humor. Third, those jokes are explainable on Grice's Cooperative Principle and Berger's rhetorical techniques.

Fourth, the Knowledge Resources of GTVH are applicable on the jokes. The third is Aroma (2011) on the tittle "Humour in Terry Pratchett's Discworld series - application of psychological and Linguistic Theory of Humor". The methods used to analyze the humor are Psychological theories of humour (socialbehavioural, psychoanalytical and cognitive perceptual) and linguistic theory of humor (SSTH and GTVH). There are three findings. First, lower-level ambiguity or incongruity is rated lower in its funniness, whereas the higher linguistic level of ambiguity or incongruity is rated higher in funniness.

Second, the linguistic device used is ambiguity or incongruity. Third, linguistic devices are not enough to understand humor; it needs the psychological ones. The fourth is Alexandru (2013) on "Funny Comment, Sad Context: A Literary and Linguistic Analysis of Humor in Kurt Vonnegut's Novels". This is a humor research using literary analysis (relating humor and the theme) and linguistic analysis (GTVH) on Vonnegut' novels Cat's Cradle, Slaughterhouse Five and Deadeye Dick. On literary analysis, Cat's Cradle is humor about meaning of life; Slaughterhouse Five is humor on the horror and absurdity of war, death and Tralfamadorian philosophy; and Deadeye Dick is humor on the importance of disarmament and the consequences, both factual and potential, of ignoring this 'holy word' and continuing with humanity's obsession with weapons. On linguistic analysis, there have been knowledge resources analysis, line position detection, humorous technique, but there is no general conclusion about them. What I have to conclude from the previous studies are; first the text analyzed are ranged from simple enough (e.g. Amalisa 2003 and Rochmawati 2011) to very large (e.g. Aroma 2011 and Alexandru 2013); second the theory used to analyzed is not focused on GTVH (all previous studies).

In the present study, the text analyzed is not a simple joke, but it is humorous narrative. Recognizing comicality in a humorous narrative is more difficult than in a joke. From its structure, a joke is quite simple. It consists of two elements; setup and a punch line [23], or what we think is going to happen (the set up) and what happens (punch line) [14]. When punch line or what happens contradicts with the set up or what we think is going to happen, here is a humor.

Therefore, the last part of the joke (the punch line) must be the funniest part. On the other hand, in humorous narrative, it is hard in locating the funniest part of the text since the humor scattered along the text [4]. In a humorous narrative, there are not only punch lines but also jab lines, but the humorous technique in an entertaining narrative is much more numerous.

The capability to recognize and understand humor is so-called humor competence. Vega [37] said, "Humor competence requires integration of knowledge of many facets. To be adept with humor one must possess knowledge of the world, sociolinguistics, discourse, grammar and culture". At a deeper level, humor competence is the capacity of a speaker to process a given text semantically and pragmatically that is to locate a set of relationships among its components, such that they can identify the text (or part of it) as humorous in an ideal situation [3].

One theory of humor that provides a formal model of humor competence is Semantic Script Theory 
of Humor (SSTH). As stated by [4] "Methodologically, the SSTH was a big step forward: it established both the semantic/pragmatic foundation of humor and the idea of studying the humor competence of speakers". In line with this, [2] states, "the SSTH is meant to account for the native speaker's humor competence". The SSTH is a formal theory that makes predictions and can be tested against "hard facts"; therefore, there is little argument that the SSTH is the most powerful epistemologically and promising theory available in the field of linguistic-based humor research.

The SSTH seems to have been accepted within the fields of sociological based humor research [28]. Here [28] presents two terms "the serious mode" and "the humorous mode". In "the serious mode" people share the same world and take for granted that other people see the world the same way as they do. Therefore, they are cooperative. There is a clear line between what is real and what is unreal. Any contradictions which are considered problematic are treated as a failure in communication. "In the humorous mode" contradictions are not problematic because incongruity is employed for a certain purpose.

General Theory of Verbal Humor (GVTH) is a broadened scope of SSTH. If SSTH is a semantic theory of humor, GVTH will be linguistics at large [4]. These broadenings are achieved by the introduction of five Knowledge Resources (KRs) that must be employed into when generating humor). The KRs are the script opposition (SO), the logical mechanism (LM), the target (TA), the narrative strategy (NS), the language (LA), and the situation (SI).

This theory is not only applicable to joke, but also humor at large such as short story, novels and conversations [2]. This theory is applicable to humor translation (young, 2007:981-988; Zabalbeascoa, 2005:185-207; Veiga, 2009). Archakis and Tsakona (2005:41-48) exploit this theory to analyze humorous conversational data. This theory is also applicable in different language as such Persian jokes (Ghafourisaleh and Modarresi, 2013: 2792-2795), and American Sign Language (Goldberg, 2010). Humorous comic such as Donald Duck can be analyzed by GTVH (Koponen , 2004).

David Sedaris' Me Talk Pretty One Day is a very funny narrative essay for many reasons. First, it is the winner of the Thurber Prize for American Humor at 2001. it is the only recognition of the art of humor writing in the United States. Secondly, this book is also praised to be humorous by some institutions or persons. The first is from the New Yorker.

Compared to Twain and Hawthorne, David Sedaris has become one of the best-loved humorists of our time, writing with perfect pitch about the ludicrousness of our age. Featuring some pieces about his sojourn in Paris that have been published and many that have been featured in The New Yorker, Esquire, and on NPR, this is a hilarious collection that shouldn't be missed.

Secondly, Entertainment Weekly stated, "The sort of blithely sophisticated, loopy humor might have resulted if Dorothy Parker and James Thurber had a love child." Thirdly, John Foyston (Portland
Oregonian) said "One of the most sustained bursts of humor in recent memory...Sedaris manages to make something bigger and more enduring out of his humor, in much the manner Mark Twain used humor as a lens through which to examine humanity".

Fourthly from Francine Prose in Washington Post Book World he said "Shrewd, wickedly funny. These hilarious, lively, and breathtakingly irreverent stories made me laugh out loud more often than anything I've read in years."

Being the winner of Thurber Prize, I thought there would be a lot of fun in each paragraphs or chapters on David Sedaris' Me Talk Pretty One Day. However, I only found one chapter (the big boy) is the most hilarious one. On the other chapter, I only find very little humor. The worst thing is declared by Leila (in sintingbuku.blogspot.com) "David Sedaris' Me Talk Pretty One Day is humor book, where is the humor?" If we relate this to the White's quip, the book or the humor in this book has already been dead or agony. In addition, I would like to make the humor alive again is by analyzing it, so the basic elements of the humor in this book become self-evident. Moreover, the prominent theory to find the humor in this book is GTVH. Those are the story behind "Dissecting Humor on David Sedaris' Me Talk Pretty One Day by Applying General Theory of Verbal Humor".

As David Sedaris' Me Talk Pretty One Day' is humorous narrative and GTVH can be used to analyze the funniness of the text, so the question are stated as follows; First, which parts of the text are humorous in terms of GTVH Knowledge Resources? Second, how does David Sedaris deliver the humor in his book? The Purposes of the Study In line with the statement of the problems, the purposes of the study are: First, to locate parts of the text that are humorous in terms of GTVH knowledge resources, Secondly, being able to find those Knowledge Resource, hopefully David Sedaris's humorous technique can be generated.

The main theory used to answer the question is SSTH (Semantic Script Theory of Humor) and GTVH (General theory of verbal humor). According to SSTH text can be characterized as a single-joke-carrying text if: The text is compatible, fully or in part, with two different scripts and the two scripts with which the text is compatible are opposite in a special sense From this hypothesis we can deduce that to understand humor we must first understand the script of words and second know in what way the scripts are opposite/overlap.

GTVH is the revision from SSTH by broadening its scope. Whereas the SSTH was a "semantic" theory of humor, the GTVH is a linguistic theory "at large" -that is, it includes other areas of linguistics as well, including, most notably, textual linguistics, the theory of narrativity, and pragmatics. These broadenings are achieved by the introduction of five other Knowledge Resources (KR) that must be tapped into when generating a joke, in addition to the script opposition from the SSTH. The KRs are the script opposition (SO), the logical mechanism (LM), the target (TA), the narrative strategy (NS), the language (LA), and the situation (SI) [4]. 


\section{METHODS}

This research is intended to describe/analyze/explain why some parts of the text in the David Sedaris' Me Talk Pretty One Day are funny. Therefore, this study qualifies as descriptive research (descriptive qualitative research). As stated by Cohen et al. (2007:205).

Such studies (descriptive research) look at individuals, groups, institutions, methods and materials in order to describe, compare, contrast, classify, analyse and interpret the entities and the events that constitute their various fields of inquiry.

Further Kothari (1990:3) said that "The main characteristic of this method is that the researcher has no control over the data; he can only report what has happened or what is happening".

\section{A. Data Collection Method}

1. Source of The Data

The source of the data is 7 chapters from David Sedaris' Me Talk Pretty One Day. They are Go Caroline (GC), Giant Dreams Mid get Abilities (GDMA), You Can't Kill the Rooster (YCKR), The Youth in Asia (YA), Big Boy (BB), Me Talk Pretty One Day (MTPOD), and Jesus Shaves (JS).

\section{Data Collection Technique}

The data analyzed is collected by observation. This is done by reading comprehension of the text. The procedures of collecting data are as follows:

a) The Preparation of Data Collection

Before the activity of collecting data is taken place, there will be indicators how to select the data that is funny or potentially funny in the essay collection David Sedaris' Talk Me Pretty One Day. They Are:

1) Identifying the level of narrative. Narrative in a given text is symbolized as level $_{n}$, Narratives introduced as narratives within the (macro) narrative are said to occur at level $_{\mathrm{n}-1}$. Any narrative occurring at level $_{\mathrm{n}}$ is said to be a metanarrative in relation to the narrative in the level $_{\mathrm{m}>\mathrm{n}}$. So narrative text can be leveled through level $_{1}$, level $_{2}$, level $_{3}$, level $_{4}$, level $_{n}$. These series of levels is called storyline. Within each level in the storyline may exist micronarrative (e.g. level $_{1-1}$ ) or metanarrative $\left(\right.$ level $\left._{1>1}\right)$ [4].

2) Selecting words/phrase/sentence, the Script Opposition (SO) category is utilized. In this category, there will be script overlap and script opposition itself.

3) How those texts are opposed will be explained by using one of 27 Logical Mechanism (LM) criteria.

4) These oppositions are going to be explained by the criteria: object participant, instrument, activities and situation (SI).

5) In the target (TA) or the butt, the criteria used are names on individual or groups or institution.

6) How this opposition narrated (NS) or told, the criteria is descriptive, dialogue, or combination between descriptive and dialogue.

7) How is the exact wording (LA) of the humor is very large. The criteria involve on linguistics, pragmatics or semantics. One of many criteria are: idiom, understatement, alliteration, coordinating conjunction, paronyms, repetition, registers marker, quotation, etc. note that LA is very important when the humor is in the form of pun.

b) The Implementation:

In identifying the level of the narrative, the symbols used are simply 'level $\mathrm{n}_{\mathrm{n}}$, level $_{\mathrm{n}-1}$, and level $\mathrm{l}_{\mathrm{m}>\mathrm{n}}$. These will be located at the marginal note.

After the script opposition is detected, the word/ phrase/sentence is underlined (dash line for jab line and straight line for punch line) and numbered in ascending order. The explanation of the underlined is placed underneath the text analyzed. Within KRs, elements separated by semi-colons are alternatives; those separated by commas are elaborations. Comments follow the six KRs listing. The abbreviation irr for irrelevant, na for not applicable.

\section{B. Data Analysis}

Procedure and the presentation of data analysis are as following steps:

1. Data Reduction

It is a form of analysis that sharpens, sorts, focuses, discards, and organizes data in, such a way that "final" conclusions can be drawn and verified. Qualitative data can be reduced and transformed in many ways: through selection, through summary or paraphrase, through being subsumed in a larger pattern, and so on. As data collection proceeds, further episodes of data reduction occur (writing summaries, coding, teasing out themes, making clusters, making partitions, writing memos) (Miles and Huberman, 1994:10-11)

In this study, data reduction is done by data presentation and analysis.

a. Data Reduction Presentation

The presentation of data reduction is done by selecting, coding, clustering, and writing memos. The obvious steps are presented at the data collection technique There are also some explanations why the text is funny underneath them.

b. Analysis

Reading those data reduction may bring confusion, especially for reader who does not familiar with General Theory of Verbal Humor (GTVH). On the other hand explaining humor through their script opposition (SO) must be a hard work as each chapter has around 100 SOs.

In this analysis, I propose only to explain SOs that leading to the plot of the story. Therefore, the analysis will be the explanation of SOs in sentences or paragraphs in exposition, raising action, climax, falling action and denouement.

\section{Data display}

A display is an organized, compressed assembly of information that permits conclusion drawing and action. Forms of the display that can be applied are matrices, graphs, charts, and networks (Miles and 
Huberman, 1994:10-11). In this study, the display chosen is matrix display. This display consists of rows and columns. Some matrices will be presented data findings and discussion.

\section{Interpretation}

Qualitative research ignores numbers. However, in certain case numbers are needed. Indeed, if we want to understand the world, words and numbers are needed. The conclusion itself can be drawn in many ways. Miles and Huberman (1994:245-262) have listed 13 ways how to generate meaning. One of them is counting.

The reasons to use counting are to see rapidly what you have in a large batch of data; to verify a hunch or hypothesis; and to keep yourself analytically honest, protecting against bias. There are two aspects:

a. The typology of script opposition (SO) and logical mechanism (LM)
$\mathrm{SO}$ is chosen as in every humor there is must be an opposition or. This opposition will be understood when the LM is clear. The typology of these knowledge resources can be seen in table 1 .

b. The typology of humor technique

The typology of humorous technique according to GTVH actually can be observed at narrative level combined with the category of line, logical mechanism (LM) and narrative strategy (NS). The result is presented in Table 2.

\section{RESEARCH FINDINGS}

In this first part, they are aimed to answer the research questions "Which parts of the text are humorous in terms of GTVH Knowledge Resources?" and "how does David Sedaris deliver the humor in his book?" The way to answer the questions are by providing the findings in the following table

Table 1

Typology of SO and LM

In seven chapters in Me Talk Pretty One Day

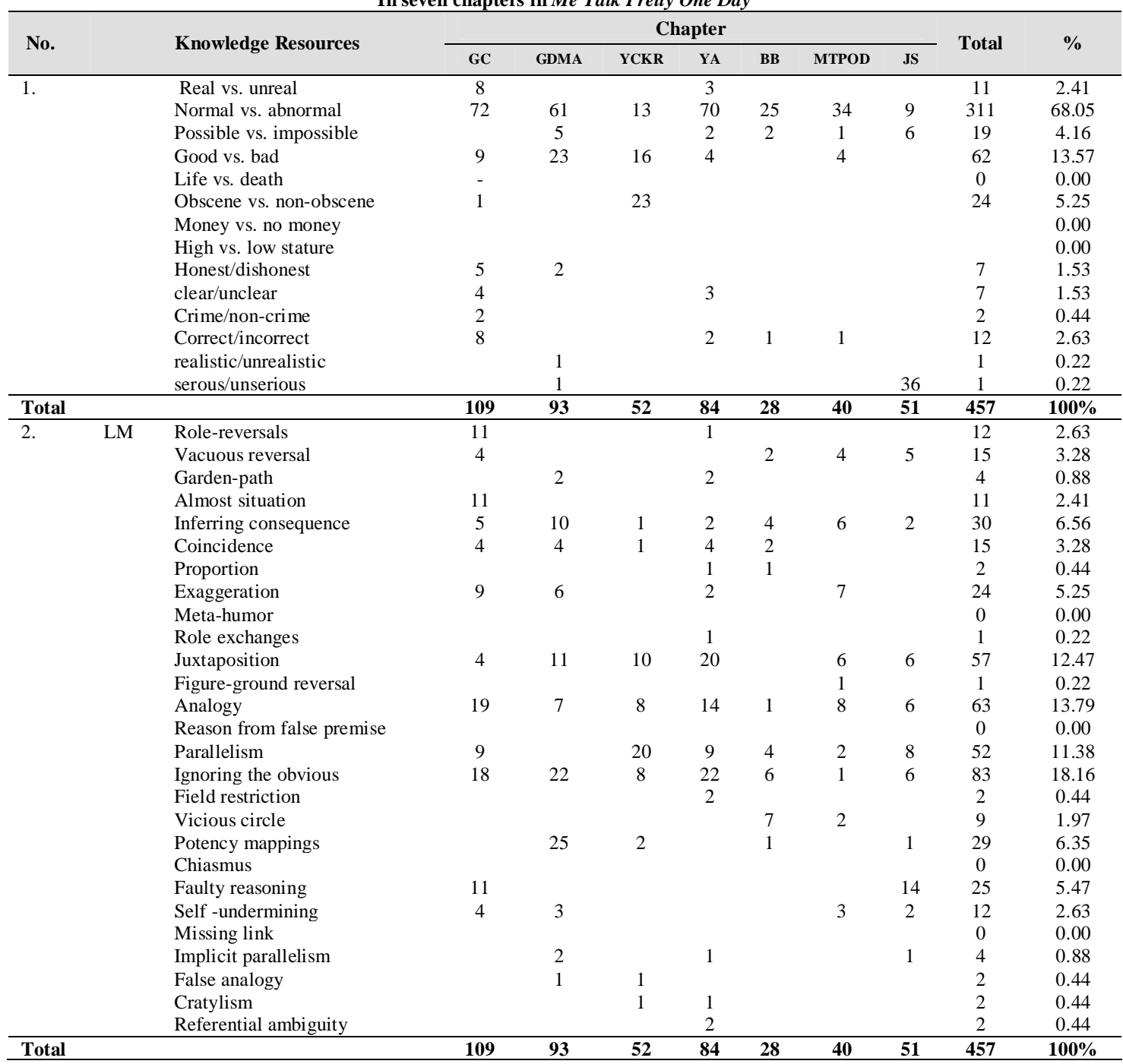


Table 2

Humorous Techniques used by David Sedaris

The Seven chapters in Me Talk Pretty One Day

\begin{tabular}{|c|c|c|c|c|c|c|c|c|c|c|}
\hline \multirow{2}{*}{ No } & \multirow{2}{*}{\multicolumn{2}{|c|}{ Humorous technique }} & \multicolumn{7}{|c|}{ Chapter } & \multirow{2}{*}{ Total } \\
\hline & & & GC & GDMA & YCKR & YA & BB & MTPOD & JS & \\
\hline 1 & Serious text & With Jab line & - & - & - & - & - & - & - & - \\
\hline \multirow{2}{*}{$\begin{array}{l}2 \\
3\end{array}$} & \multirow[t]{5}{*}{ Humorous text } & Ending with punch line & 30 & 24 & 17 & 24 & 9 & 18 & 9 & 131 \\
\hline & & $\begin{array}{l}\text { Using metanarrative } \\
\text { disruption }\end{array}$ & 14 & 17 & 1 & 4 & 0 & 0 & 0 & 36 \\
\hline 4 & & Using coincidences & 5 & 4 & 1 & 4 & 2 & - & 1 & 17 \\
\hline 5 & & Hyper determined humor & - & - & - & - & - & - & - & - \\
\hline \multirow[t]{3}{*}{6} & & Using diffuse disjunction & 60 & 48 & 33 & 52 & 17 & 22 & 41 & 273 \\
\hline & \multirow{2}{*}{\multicolumn{2}{|c|}{ Total lines }} & 109 & 93 & 52 & 84 & 28 & 40 & 51 & 457 \\
\hline & & & 3359 & 4210 & 2079 & 3491 & 725 & 1820 & 1606 & 17290 \\
\hline
\end{tabular}

\section{DISCUSSION}

In this part, it will discuss about the relation between this work and the previous studies, GTVH knowledge resources, and humorous technique.

\section{A. GTVH Knowledge Resources}

In the previous chapter, it is stated that all GTVH Knowledge Resources (SO, LM, TA, SI, NS, LA) must be tapped in order to understand the humor. In fact, this is not necessarily true or important.

Understanding the script opposition (SO) and its logical mechanism (LM) is adequate to perceive the humor. These knowledge resources are very important as they represent the joke or humor schema. The other knowledge resources such target (TA) and situation (SI) are still important but can be found easily in text, especially in the long humorous narrative text. In fact, the situation (SI) resembles the topic sentence of a paragraph. The function of the situation (SI) is to help reader to understand the script opposition (SO).

If the script opposition (SO) is fully grasped, the situation can be ignored. On the narrative strategy (NS), much humor in narrative text is delivered through comment. Finally the wording of joke or humor (language, LA) do not apply much.

Therefore, the basic knowledge resources needed in understanding the humor in narrative text is the script opposition and logical mechanism. Below the discussion of script opposition and its logical mechanism in the text analyzed will be presented.

\section{Script opposition}

Understand humor is understand script opposition. Normal/abnormal dominates the opposition among the script. In this way, the ability to see something abnormal requires the knowledge of psychology, culture, society etc. Then it becomes complicated. In the field of humor, to simplify the problem, normal means expected by the narrator or reader; abnormal means unexpected by the narrator or the reader.

Anyway, to find the abnormality in chapter $\mathrm{Me}$ Talk Pretty One Day and Jesus Shaves need the knowledge of Christianity. As the script opposition are scattered along the text, the humor can be find everywhere in the text. This is different from joke that only have one humor or punch line (research done by Amalisa and Rochmawati). As they are scattered along text, the humor can be easily pass unnoticed.

\section{Logical Mechanism}

From the logical mechanism of how a script opposites each other, there have been 24 categories. To simplify the discussion, they then can be classified into reasoning, syntagmatic relation and ambiguity (Wulf: 2010).

Humor is the power of reasoning. Reasoning whether it is correct, faulty or Meta can be amusing. Correct reasoning is funny if it contains inappropriateness or local logic. This can be done by almost situation, analogy, coincidence, inferring consequence, reason from false premise, and missing link.

Much humor can be start originated on the faulty reasoning. As stated by Hurley (2011) that "humor is provoked by recognition of error". Error often emerges on cratylism (pun), exaggeration, and false analogy, field restriction, ignoring the obvious and faulty reasoning.

Some opposition of the scripts are available in the text. This kind of opposition is labeled as syntagmatic relation or opposition. They can be direct spatial such as vicious circle, juxtaposition, parallelism, proportion, or implicit parallelism. Some can be reversal, such as role exchanges, potency mappings, chiasmus, figure-ground reversal, vacuous reversal, or role-reversals. Moreover, the other can be the ambiguity.

\section{Humorous Technique}

The humor in David Sedaris is delivered through ending with punch line, metanarrative disruption, coincidences and diffuse disjunction. Much humor in this book is transported by diffuse disjunction, this can bring the humor cannot be easily perceived. In diffuse disjunction, the meaning contradiction between the texts is not easily traced. This situation then can be characterized as humorous irony. This diffuse disjunction actually serves as jab line. This jab line occurs anywhere in the text, (except, obviously, at the end, as they would then be punch line).

The difference between jab line and punch line cannot be easily determined relating to this study. The complication is the contradiction between the theory and the application. It is stated that punch line is having final position in the text and disruptive to the content of the story. However, some lines of the 131 
final punch lines are non-disruptive. The question is whether we use the position of line or the function of the line to resolve jab or punch line.

Much humor on David Sedaris' Me Talk Pretty One Day is not only presented in the storyline or narrative (leveln), but also in the form of comment either in the metanarrative level (levelm>n) or micronarrative level (leveln-1). Since humor can happen in micronarrative level, we may call it micronarrative humor. Moreover, few metanarrative disruptions serve as punch line. Finally, as it is not the $\mathrm{w}$, ork of non-sense humor, only few humorous coincidences are discovered.

\section{The relation to the previous studies}

a. The structure of joke and humorous narrative is proven quite different. There is not only punch line but also jab lines. Determining which one is the punch line in humorous narrative is troublesome.

b. Understanding background knowledge of a script is very important for non-native speaker to perceive the humor. However, some humors found in David Sedaris' Me Talk Pretty One Day are universal, so the background knowledge is not much needed. Of course, it is depend on knowledge and experience.

c. The key element of finding the humor is actually finding the script opposition or incongruity. So that SSTH and GTVH are actually adequate.

\section{CONCLUSION}

From the sample data analyzed, it is established that David Sedaris' Me Talk Pretty One Day is funny. It is reinforced by the 457 script opposition discoveries. Theoretically, all GTVH knowledge resources (SO, LM, TA, SI, NS, LA) have to be applied. Practically, it is not necessary. The first thing to be done in finding the humor in a text is discovering the script opposition ( $\mathrm{SO}$ ). If this script opposition is fully grasped, the other knowledge resources is not necessary to be found. This is linear with GTVH knowledge resource hierarchy that script opposition is in top position. Consequently, it must be said that SSTH is also possible and sufficient to be applied to humorous narrative. On the other hand, if the script opposition is not fully understood, the other knowledge resources must be used to handle the problem. Here GTVH is much needed.

In Humorous Technique, GTVH gives six alternatives for deciding the humorous techniques in a text. Only few of them are applicable. The typical achieved humorous techniques listed from the most to the less, are as follow:

a. Diffuse disjunction

In this humorous technique, 273 lines or $59.74 \%$ from whole lines have been obtained. This is the reason why it is hard to find humor in narrative. It indicates that much form of humor in this narrative is irony.

b. Punch line

In this category, 131 lines or $28.35 \%$ have been found. c. Metanarrative disruption

Some of the humors are found outside of the storyline or metanarrative. 36 lines or $7.88 \%$ in this type prove it.

d. Coincidence

There are only 17 lines or $3.72 \%$ from the overall lines. It means that David Sedaris's Me Talk Pretty One Day is not a

\section{ACKNOWLEDGMENT}

Praise be to Allah, The cherisher and sustainer of the worlds; God who has been giving His blessing and mercy, so that this research finally could be completed Shalawat and Salaam to the Prophet Muhammad SAW and $h$ is family. In the research, I also would my gratitude to Prof. Dr. Abbas A. Badib, MA., MA., who has given his best guidance to write a quality content. Drs. Suwono, Ph.D, who has given her help to show the best way to research.

\section{REFERENCES}

[1] Asher, N. Lexical Meaning in Context. United Kingdom: Cambridge University Press, 2011

[2] Attardo, S. Linguistic Theories of Humor. New York: Mouton de Gruyter. 1994.

[3] Attardo, S. Humor and Irony in Interaction: From Mode Adoption to Failure of Detection. In Luigi Anolli, Rita Ciceri, Giuseppe Riva (ed.) Say Not to Say: New Perspectives on Miscommunication. Amsterdam: IOS Press, 2002.

[4] Attardo, S. Humorous Texts: A semantic and pragmatic analysis. New York: Mouton de Gruyter, 2001

[5] Billig, M. Laughter and Ridicule Towards a Social Critique of Humour . London: SAGE Publications Ltd, 2005.

[6] Carlin, G. Brain droppings. New York: Hyperion Books, 1998.

[7] Carmen, P. Understanding ethnic humour in Romanian jokes. In Marta Dyne, (ed.) The Pragmatics of Humour across Discourse Domains. Amsterdam: John Benjamins Publishing Company, 2011.

[8] Chatman, S. Story and Discourse: Narrative Structure in Fiction and Film. New York: Cornell University Press, 1978.

[9] Davies, Ce. Ethnic Humor around the World. Bloomington: Indiana University Press, 1990.

[10] ZoltanDornyei. Research Methods in Applied Linguistics. Oxford University Press, 2007.

[11] Flemming, L. Reading for Thinking. Boston: Wadsworth, 2012.

[12] Fcllbaum, C. WordNet, an electronic lexical database. London: Massachusetts Institute of Technology.

[13] Frey, L., Botan, C., \& Kreps, G. 1999. Investigating communication: An introduction to research methods.(2nd ed.) Boston: Allyn\& Bacon. 1998.

[14] Gene, P. How to write and sell your sense of humor. Ohio: Writer's Digest Books, 1982.

[15] Grice, H. P. Studies in the Way of Words. London: Harvard University Press. (1975).

[16] JoeSachs. Aristotle Poetics. Newburyport MA: Focus Publishing, 2006.

[17] Glenn, E. W. The Adaptive Value of Humor and Laughter. DOI Journal vol. 14 issue 2 1993. New York: Elsevier Science Publishing Co., Inc., 1993.

[18] Hackforth, R. Plato's Examination of Pleasure. Cambridge At The University Press. 1945. 
[19] Hulstijn, J. and Nijholt A. (eds.). Automatic Interpretation and Generation of Verbal Humor. Proceedings of the Twelfth Twente Workshop on Language Technology.UniversitcitTwente, Enschede. 1996.

[20] Haiman, J. Talk Is Cheap: Sarcasm, Alienation, and the Evolution of Language. New York: Oxford University Press, 1998..

[21] Koestler, A. The Act of Creation. London: Hutchinson \& Co. Ltd. 1964.

[22] Labutov, I., and Lipson, H. Humor as Circuits in Semantic Networks. Proceedings: Proceedings of the 50th Annual Meeting of the Association for Computational Linguistics. Korea: Association for Computational Linguistics.

[23] Martin, R. A. The Psychology of Humor: An Integrative Approach. UK: Elsevier Academic Press. 2007.

[24] Mey, J. L. Conciseencyclopedia of Pragmatics. United Kingdom: Elsevier Ltd. 2009.

[25] Morreall, J. Philosophy and religion. In Victor Raskin and Willibald Ruch, (ed.) The Primer of Humor Research. Berlin: Mouton de Gruyter. 2008.

[26] Morreall, J. Comic Relief: A Comprehensive Philosophy of Humor. United Kingdom: John Wiley \& Sons Ltd. 2009.

[27] Morreall, J. Taking laughter seriously. Albany, NY: State University of New York Press. 1983).

[28] Mulkay, M. On Humor: Its Nature and its Place in Modern Society. Cambridge: Blackwell. 1988.

[29] Murphy, M. L. Semantic Relations and the Lexicon: Antonymy, Synonymy, and Other Paradigms. United Kingdom: Cambridge University Press. 2003.

[30] Nancy D. B.2011. Humor Scholarship and TESOL: Applying Findings and Establishing a Research Agenda. Washington State University.

[31] Nirenburg, S., and Raskin, V. Ontological Semantics. London: Massachusetts Institute of Technology. 2004.

[32] Phillip, G. Laughter in Interaction. New York: Cambridge University Press, 2003.

[33] Raskin, V. Semantic mechanisms of humor. Lancaster: D. Reidel Publishing Company. 1944.

[34] Raskin, V. The primer of humor research. New York: Mouton de Gruyter. 2008.

[35] Raymond, W. G., and Herbert, L. C. Irony In Language and Thought: A Cognitive Science Reader. New York Lawrence Erlbaum Associates. 2007.

[36] Ross, A. The Language of Humour. London: Routledge. 1998.

[37] Sarah E. J. American Humor: Should it be Taught? A Look at Cultural Appreciation and Understanding of American Humor. DLLS Proceedings. Brigham Young University. 1992.

[38] Sedaris, D. Me Talk Pretty One Day. USA: Little, Brown and Company. 2000.

[39] Simpson, J. A., \& Weiner, E. S. C. The Oxford English dictionary (2nd ed., Vol. 7). Oxford:Clarendon Press. 1989.

[40] Sperber, D., and Wilson, D. Relevance: Communication and Cognition. United Kingdom: Blackwell Publishers Ltd. 1986.

[41] Strapparava, C., Oliviero, S., and RadaMihalcea. Computational Humour. In P. Petta et al. (eds.) Emotion-Oriented Systems. Verlag Berlin Heidelberg: Springer. 2011.

[42] Vandaele, J. Narrative Humor (I): Enter Perspective. Spanish: Porter Institute for Poetics and Semiotics, 2011.

[43] White, E. B., and White, K. S.. A Subtreasury of American Humor. New York: Wolff Boob Mfg. Co., 1991. 